\title{
Association between blood pressure and acute phase stroke case fatality rate: a prospective cohort study
}

\author{
Associação entre níveis de pressão arterial e letalidade na fase aguda do acidente \\ vascular cerebral: estudo de coorte prospectivo
}

Natalia Eduarda Furlan',2, Silméia Garcia Zanati Bazan¹, Gabriel Pereira Braga', Meire Cristina Novelli e Castro', Roberto Jorge da Silva Franco', Ana Lúcia Gut', Rodrigo Bazan', Luis Cuadrado Martin'

\begin{abstract}
Objective: ed to investigate the association between blood pressure and acute phase stroke lethality in a Brazilian intensive care unit. Methods: This was an observational, prospective cohort study of hemorrhagic and ischemic stroke intensive care patients. The primary outcome was all-cause mortality during the first seven days. Results: There were 146 patients, aged $66 \pm 13.4$ years, $56 \%$ men, $89 \%$ Caucasian, $69 \%$ had ischemic stroke, and $80 \%$ were hypertensive. The median of the National Institutes of Health Stroke Scale score was 16. There were 101 ischemic stroke patients and 45 hemorrhagic stroke patients. In the ischemic stroke patients, logistic regression analysis identified low systolic blood pressure as an independent ominous prognostic factor and the optimal cut off was a mean of systolic blood pressure $\leq 131 \mathrm{mmHg}$ during the first 48 hours from admission for prediction of death. No association was found for hemorrhagic stroke. Conclusions: There was a negative association between systolic blood pressure and case fatality ratio of acute phase stroke in ischemic stroke intensive care patients.
\end{abstract}

Keywords: stroke; blood pressure, hypertension.

RESUMO

Objetivo: Investigar a associação entre pressão arterial e letalidade do acidente vascular cerebral (AVC) em uma unidade de terapia intensiva brasileira. Métodos: estudo de coorte prospectivo de pacientes com AVC hemorrágico (AVC-H) ou isquêmico (AVC-I) internados em terapia intensiva. 0 desfecho primário foi a letalidade por todas as causas nos primeiros sete dias. Resultados: Avaliados 146 pacientes, idade: $66 \pm 13,4$ anos, $56 \%$ homens, $89 \%$ brancos, 69\% AVC-I e 80\% hipertensos. A mediana do NIH foi de 16. Os pacientes com AVC-I foram 101 e 45 com AVC-H. Para AVC-I, a análise de regressão logística identificou baixa pressão arterial sistólica como um fator prognóstico negativo e o melhor corte foi uma média da pressão arterial sistólica nas primeiras $48 \mathrm{~h}$ de admissão $\leq 131$ mmHg para a predição da morte. Para o AVC-H, nenhuma correlação foi encontrada. Conclusões: houve associação negativa entre a pressão arterial sistólica e a letalidade do AVC-I em fase aguda em pacientes de terapia intensiva.

Palavras-chave: acidente vascular cerebral; pressão arterial, hipertensão.

Stroke is one of the leading causes of death and disability among adults in Brazil and worldwide ${ }^{1,2,3}$. Fifteen million people suffer from a stroke annually, of whom five million die and another five million become disabled ${ }^{1,2,3}$. Arterial hypertension is the major modifiable cause of stroke ${ }^{4,5}$. In addition, blood pressure (BP) control is a priority in stroke prevention ${ }^{6,7,8,9}$.

Nevertheless, few studies have evaluated the relationship between arterial hypertension in the first 48 hours of stroke onset and the case fatality rate. In the acute phase of stroke, $80 \%$ of patients present with elevated $\mathrm{BP}^{10}$. High $\mathrm{BP}$ can produce hematoma enlargement in hemorrhagic stroke (HS). On the other hand, in ischemic stroke (IS), high BP during this phase can induce cerebral edema and hemorrhagic transformation $^{10}$. Alternatively, low BP can lead to low perfusion of the ischemic penumbra zone, which leads to enlargement of the stroke area ${ }^{11,12}$.

\footnotetext{
${ }^{1}$ Universidade Estadual Paulista Julio de Mesquita Filho, Faculdade de Medicina, Botucatu SP, Brasil;

${ }^{2}$ Serviço Nacional de Aprendizagem Comercial, Botucatu SP, Brasil.

Correspondence: Luis Cuadrado Martin; Rua RubiãoJr, s/n; 18618-970 Botucatu SP, Brasil; E-mail: cuadrado@fmb.unesp.br

Clinical Trial registration number: NCT01195350.

Conflict of interest: There is no conflict of interest to declare.

Received 28 June 2017; Received in final form 21 February 2018; Accepted 04 April 2018.
} 
Through these mechanisms, the relationship between BP and death during the acute phase of stroke depicts a "U" shape in many studies, i.e. both low and high BP extremes are associated with a higher chance of death ${ }^{11,13,14,15}$. Other studies have demonstrated a direct relationship ${ }^{16,17}$. For critical care stroke patients, these mechanisms may play a significant role in survival too. However, information is limited on the impact of BP on the case fatality rate of strokes in the intensive care unit (ICU). Some studies have evaluated other prognostic factors of stroke in the ICU ${ }^{18,19,20,21,22,23,24}$. However, we identified only one study performed in the ICU evaluating BP as a prognostic factor; but the evaluation was performed only for the first 12 hours after onset and did not mention any association with death ${ }^{25}$. Therefore, the aim of the present study was to evaluate the relationship between BP and fatality during the acute phase of stroke in critical care patients.

\section{METHODS}

We conducted an observational, prospective cohort study in the ICU of a tertiary hospital of Botucatu Medical School - São Paulo State University (UNESP) in Brazil. The participants included were patients over 18 years old, who were admitted to the ICU with a stroke from March 2012 to April 2016 during the study time period. The criteria for stroke patients for the ICU admission were: vasopressor drug use due to hemodynamic instability and/or depressed consciousness and/or invasive ventilation. All survivors of the initial stroke event stayed in the ICU for at least seven days. We excluded patients with subarachnoid hemorrhage or incomplete records. All patients underwent computed tomography of the head.

Age, gender, ethnic group, stroke type, occurrence of infection or myocardial infarction during ICU hospitalization, and previous diagnosis of hypertension or diabetes were recorded. Stroke evaluation and BP measurements were performed on admission and every two hours thereafter, throughout the patient's first week in the ICU. Stroke was evaluated with the National Institutes of Health Stroke Scale (NIHSS) ${ }^{26}$. Noninvasive automatic BP measurements were taken with a multiparameter monitor (Dixtal') with the cuff positioned on the patient's arm. The first BP was analyzed on admission, with a mean of 48 hours and the variation was quantified by the coefficient of variation (standard deviation divided by mean) of the first 48 hours. Body temperature was measured every two hours and capillary blood glucose every six hours throughout the first week. On admission, laboratory tests were performed for glucose and creatinine.

This study was approved by the local ethics committee, protocol number: 3429 01/February/2010, and was registered in the Clinical Trials database (NCT01195350). The few patients who were conscious, alert and oriented gave their written informed consent. Legal representatives signed consent agreements for unconscious patients.

\section{Statistical Analysis}

All patients were analyzed in two sets separately according to the stroke subtypes. The sample size was calculated to detect a $30 \%$ difference in the case fatality ratio with an alpha error of 0.05 and statistical power of 0.9 ; this resulted in an estimated required sample size of 132 patients.

Variables were described as mean \pm standard deviation. Patients were divided into two groups: patients alive within seven days and patients deceased during this period. All evaluated data from these two groups were compared to each other. Univariate analysis was performed by the Chi square test to compare categorical variables and the T-test to compare continuous variables.

After this univariate analysis, a backward stepwise multiple logistic regression was performed. The dependent variable of logistic regression was death during the first seven days of stroke. The association between BP and death was adjusted for variables that differed at $\mathrm{p}<0.1$ in univariate analysis (confounders). After backward analysis, variables with $\mathrm{p}<0.1$ were preserved in the final model. Only in these phases of analysis, the different $p$ value used was set to identify variables that, by themselves, were not statistically associated with the outcome, but could contribute to the model together with other variables ${ }^{27}$. The collinearities were tested and, if present, the more representative variable was selected. Statistical significance was set at $\mathrm{p}<0.05$.

An ROC curve was performed to verify the discriminatory power of BP to case fatality. The optimal cut off was determined by the higher sum of sensibility and specificity (Youden Index). Sensibility and specificity for this cut off was calculated. All analysis was performed using SPSS20.0 software (Illinois Chicago).

\section{RESULTS}

During the study period, there were 1,432 admissions for stroke to our hospital. Of these patients, 260 required treatment in the ICU, 48 patients refused to give informed consent or there were difficulties obtaining informed consent in an interview with the patient's family. Therefore, a total of 212 patients were screened. There were 66 patients who were excluded due to incomplete records, and of these, 13 died in the seven first days (19\%), which is a frequency similar of the mortality of the analyzed patients. The final sample included 146 patients; 101 with IS and 45 with HS (Figure 1).

Of the patients enrolled in the study, $55 \%$ were male with a mean age was $66 \pm 13.4$ years. The predominant race was Caucasian (89\%). The NIHSS mean value 
was $16 \pm 6.5$ points. Initial mean systolic BP (SBP) was $161 \pm 40.9 \mathrm{~mm} \mathrm{Hg}$. The mean SBP in the first 48 hours after admission was $138 \pm 16.7 \mathrm{~mm} \mathrm{Hg}$.

During the first week of admission, 31 patients (21\%) died. The causes of death were intracranial hypertension in 17 patients $(55 \%)$, endocarditis in one patient (3\%), cardiogenic shock in four patients (13\%), septic shock in seven patients (23\%), and indefinite causes in two patients (6\%).

Among the patients with HS (Table 1) when comparing those who died against those who survived during the first week, the groups were similar except for sex and body temperature where differences were statistically significant. Infection was marginally associated with outcome. No BP parameter was associated with outcome. We took into account the Glasgow Coma Scale and hematoma volume, and ran a multiple regression with $\mathrm{BP}$ and these variables. Even so, BP was not correlated with outcome. The baseline SBP adjusted odds ratio (OR) and 95\% confidence interval (95\% CI) was: 1.026 (0.986-1.067); p $=0.209$. Baseline diastolic BP (DBP) OR and CI 95\% was: 1.054 (0.984-1.130); $\mathrm{p}=0.132$. The 48-hour SBP average OR and CI 95\% was: 1.003 (0.935-1.077); $\mathrm{p}=0.926$. The 48-hour DBP average OR and CI 95\% was: 1.031 (0.913-1.164); $\mathrm{p}=$ 0.620 . No patient was on anticoagulation treatment prior to the hemorrhagic stroke.

Table 2 shows comparisons between the deceased and surviving patients among those with IS, during the first week. The groups differed statistically in age, NIHSS score on admission, initial SBP, SBP in the first 48 hours, initial DBP, DBP in the first 48 hours, and occurrence of myocardial infarction. In the first 48 hours, the average of the capillary blood glucose, the coefficient of variation of SBP, and serum creatinine had a $p$ value $<0.10$. The variables of age, NIHSS score on admission, mean SBP during the first

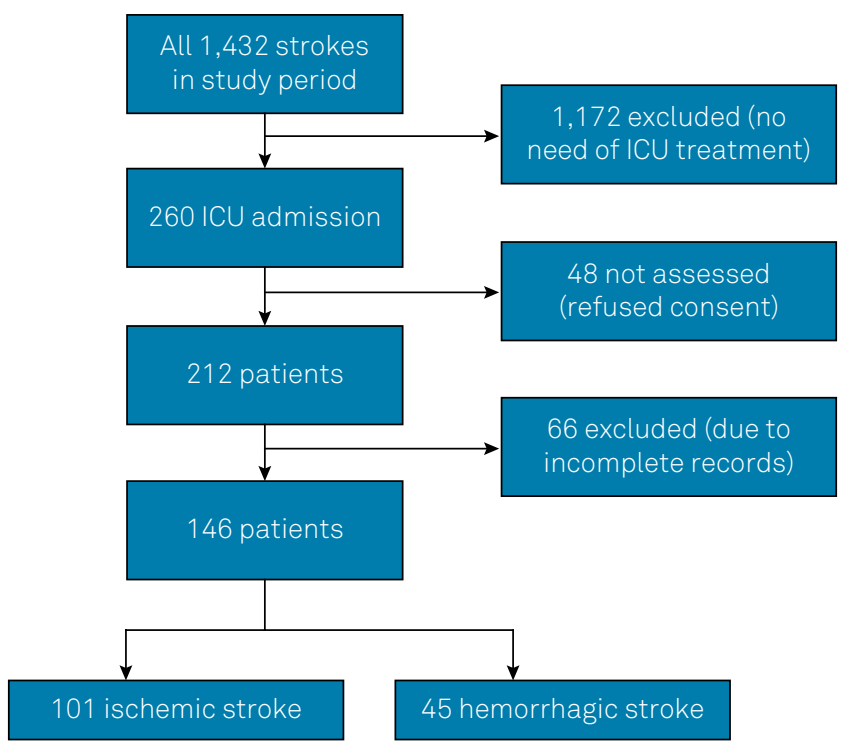

Figure 1. Flowchart of patients.
48 hours, myocardial infarction, average of the first 48 hours of capillary blood glucose, the coefficient of variation of SBP in the first 48 hours and serum creatinine were selected as predictors in a multiple logistic regression analysis. Baseline SBP and DBP, and 48-hour DBP were excluded by collinearity with the SBP mean during the 48 hours. Some antihypertensive drug classes were more commonly used among survivors than the deceased patients (angiotensin converting enzyme inhibitors: $47 \%$ vs. $9 \%$; p < 0.01; beta-blockers: $34 \%$ vs. $6 \%$; $p<0.01$ ). The frequency of use of other antihypertensive drug classes were homogeneous between survivors and deceased patients.

\section{Multiple logistic regression analysis for IS}

For the subset of IS patients, the association between SBP in the first 48 hours from stroke onset and outcome was adjusted for confounders. This model is shown in Table 3. The SBP showed a statistically significant association with all-cause mortality. The final model, including age and NIHSS score demonstrated an OR of 0.960 (CI 95\%: 0.9220.999; $\mathrm{p}=0.047$ ).

A post hoc logistic regression analysis was performed. This analysis included the mean BP in first 48 hours after stroke, myocardial infarction and occurrence of any infection (including septic shock) as confounders. In this analysis, low BP in the first 48 hours after stroke was associated with death after adjusting for these confounders (Table 4). Among the 23 deaths of IS patients, 13 were caused by intracranial hypertension, six were caused by septic shock and four by cardiogenic shock. The Hosmer-Lemeshow test was not significant for all logistic regressions ( $p$ range from 0.22 to 0.40 ), demonstrating the goodness-of-fit.

\section{ROC curve for IS}

Figure 2 shows the ROC curve. The area under the ROC curve between the 48-hour-average SBP and mortality was 0.74 (CI 95\%: 0.63-0.84; $\mathrm{p}<0.001$ ). The optimal cut off was $\leq 131 \mathrm{~mm}$ Hg. This BP cut off demonstrated a sensibility of 0.65 and a specificity of 0.67 to predict one-week mortality in the ICU.

\section{DISCUSSION}

Of the patients studied, $80 \%$ had hypertension, demonstrating the high prevalence of this risk factor in critical care stroke patients, as observed in other studies ${ }^{9,10}$. Nevertheless, few studies have evaluated the association between BP and the case fatality ratio in acute stroke. Some international studies have identified a "U" curve relationship between BP and in-hospital mortality, where both high and low BP were associated with an increased early fatality ratio ${ }^{11}$. In our study, the association between BP and the case fatality ratio in the acute phase of stroke in ICU 
Table 1. Comparison of prognostic variables by outcome during the acute phase of hemorrhagic stroke.

\begin{tabular}{|c|c|c|c|c|}
\hline \multirow{2}{*}{ Variables } & \multirow{2}{*}{ All patients $(n=45)$} & \multicolumn{2}{|c|}{ Death } & \multirow{2}{*}{$p$-value } \\
\hline & & Survived $(n=37)$ & Died $(n=08)$ & \\
\hline Age (years) & $64 \pm 13.58$ & $62 \pm 13.8$ & $66 \pm 13.1$ & 0.452 \\
\hline Male & $53 \%$ & $43 \%$ & $100 \%$ & 0.009 \\
\hline \multicolumn{5}{|l|}{ Race } \\
\hline Caucasian & $87 \%$ & $86 \%$ & $14 \%$ & \multirow{2}{*}{1.000} \\
\hline Other race & $13 \%$ & $87 \%$ & $15 \%$ & \\
\hline NIHSS on admission (point) & $17 \pm 5.8$ & $17 \pm 5.5$ & $18 \pm 8.2$ & 0.988 \\
\hline Baseline SBP (mmHg) & $173 \pm 46$ & $169 \pm 42.1$ & $191 \pm 62.9$ & 0.228 \\
\hline $48 \mathrm{~h}$ SBP average (mmHg) & $141 \pm 17.6$ & $143 \pm 16.9$ & $133 \pm 19.1$ & 0.156 \\
\hline SBP VC $48 \mathrm{~h}(\mathrm{mmHg})$ & $0.09 \pm 0.09$ & $0.10 \pm 0.091$ & $0.09 \pm 0.096$ & 0.761 \\
\hline Baseline DBP (mmHg) & $79 \pm 23$ & $98 \pm 21.5$ & $111 \pm 30.1$ & 0.154 \\
\hline $48 \mathrm{~h}$ DBP average (mmHg) & $78.4 \pm 11.9$ & $78 \pm 12.4$ & $79 \pm 10.1$ & 0.859 \\
\hline 48 h DBP VC (mmHg) & $0.11 \pm 0.09$ & $0.11 \pm 0.085$ & $0.10 \pm 0.104$ & 0.910 \\
\hline $\mathrm{T}\left({ }^{\circ} \mathrm{C}\right)$ & $36.7 \pm 0.50$ & $36.8 \pm 0.37$ & $36.4 \pm 0.87$ & 0.046 \\
\hline $48 \mathrm{~h} \mathrm{~T}$ average $\left({ }^{\circ} \mathrm{C}\right)$ & $36.6 \pm 0.60$ & $36.6 \pm 0.51$ & $36.4 \pm 0.92$ & 0.292 \\
\hline $48 \mathrm{~h} \mathrm{TVC}\left({ }^{\circ} \mathrm{C}\right)$ & $0.01 \pm 0.009$ & $0.01 \pm 0.009$ & $0.017 \pm 0.011$ & 0.078 \\
\hline $\mathrm{CBG}(\mathrm{mg} / \mathrm{dL})$ & $145 \pm 24.9$ & $146 \pm 24.9$ & $139 \pm 26.3$ & 0.455 \\
\hline 48 h CBG average (mg/dL) & $143 \pm 39.1$ & $146 \pm 41.7$ & $134 \pm 23.4$ & 0.441 \\
\hline 48 h CBG VC (mg/dL) & $0.16 \pm 0.21$ & $0.16 \pm 0.231$ & $0.14 \pm 0.109$ & 0.782 \\
\hline Infection & $47 \%$ & $54 \%$ & $12 \%$ & 0.051 \\
\hline $\begin{array}{l}\text { Acute myocardial infarction during hospitalization } \\
\text { or admission }\end{array}$ & $2 \%$ & $0 \%$ & $1 \%$ & 0.178 \\
\hline Creatinine (mg/dL) & $1.2 \pm 0.91$ & $1.2 \pm 0.93$ & $1.4 \pm 0.88$ & 0.496 \\
\hline Previous arterial hypertension & $87 \%$ & $84 \%$ & $100 \%$ & 0.572 \\
\hline Previous diabetes mellitus & $22 \%$ & $22 \%$ & $25 \%$ & 1.000 \\
\hline \multicolumn{5}{|c|}{$\begin{array}{l}\text { Data presented as the mean } \pm \text { standard deviation or percent (\%). HS: hemorrhagic stroke; NIHSS: National Institute of Health Stroke Scale; SBP: systolic BP; } 48 \mathrm{~h} \\
\text { SBP average: average of systolic BP during the } 48 \text { hours after admission; } 48 \mathrm{~h} \text { SBPVC: systolic BP variation coefficient at } 48 \text { hours after admission; DBP: diastolic } \\
\text { BP; } 48 \text { h DBP average: average of diastolic BP during the } 48 \text { hours after admission; } 48 \text { h DBP VC: diastolic BP variation coefficient at } 48 \text { hours after admission; T: } \\
\text { temperature at admission; } 48 \mathrm{hT} \text { Taverage: average of body temperature at } 48 \text { hours after admission; } 48 \mathrm{~h} \text { TVC: average of body temperature variation coefficient } \\
\text { at } 48 \text { hours after admission; CBG: capillary blood glucose; } 48 \mathrm{~h} \text { CBG VC: average of capillary blood glucose variation coefficient at } 48 \text { hours after admission; } \\
\text { Infection: infection during the first } 7 \text { days of hospitalization. Bold indicates } p<0.10 \text {, therefore inclusion criteria for multiple logistic analysis. }\end{array}$} \\
\hline
\end{tabular}

patients did not follow this expected relationship; rather there was an increase in the probability of death in the first week only among patients with low SBP $(\leq 131 \mathrm{~mm} \mathrm{Hg})$ in the first 48 hours after admission among IS patients, and no relationship for HS. In the current study, we analyzed BP and variation of $\mathrm{BP}$ during the first 48 hours of admission to exclude pre-mortem phenomena as a cause of BP abnormalities. This procedure was performed to exclude epiphenomena, such as septic or cardiogenic shock, as an explanation for the associations observed.

There were no differences in the case fatality ratio between patients with HS (18\%) and IS (23\%) in this study. This data demonstrated the profile of severity of patients in our study that evaluated only ICU patients. Alonso et al. ${ }^{28}$ found similar results in ICU stroke patients. In the current study, the NIHSS score in IS was similar to that of HS ( $16 \pm 6.7$ vs. $17 \pm 5.8)$.

The lack of relationship between BP and fatality in HS in the present work may be explained by the low average BP (141 mm Hg) that was obtained in ICU care; also, higher
SBP levels, sufficient to increase fatality, were not found in this series of patients. The fact that low BP was not associated with the case fatality ratio is in consonance with the INTERACT- $2^{29}$ study, and corroborates the safety of intensive BP intervention in HS.

The IS patients with SBP values below $147 \mathrm{~mm} \mathrm{Hg}$ at admission and $131 \mathrm{~mm} \mathrm{Hg}$ in the first 48 hours of hospitalization had a higher risk of death. These values were obtained by ROC curve analysis. The different results for IS and HS may be explained by the different pathophysiology models. In IS, the ischemic penumbra zone ${ }^{30}$, mainly in the early hours from onset of acute stroke, is relevant. On the other hand, perihematoma and vasogenic edema prevails in HS, leading to elevation of intracranial pressure.

A post hoc logistic regression analysis of our data (Table 4) showed that in IS patients, the relationship between low BP and the case fatality ratio was maintained even after adjustment for myocardial infarction and infection. This finding indicates that the effect of low BP was independent of myocardial 
Table 2. Comparison of prognostic variables by outcome during the acute phase of ischemic stroke.

\begin{tabular}{|c|c|c|c|c|}
\hline \multirow{2}{*}{ Variables } & \multirow{2}{*}{$\begin{array}{l}\text { All patients }(n= \\
101)\end{array}$} & \multicolumn{2}{|c|}{ Death } & \multirow{2}{*}{$\mathrm{p}$-value } \\
\hline & & Survived $(n=78)$ & Died $(n=23)$ & \\
\hline Age (years) & $68 \pm 13.1$ & $66 \pm 12.5$ & $75 \pm 12.8$ & 0.003 \\
\hline Male & $55 \%$ & $60 \%$ & $39 \%$ & 0.120 \\
\hline \multicolumn{5}{|l|}{ Race } \\
\hline Caucasian & $87 \%$ & $85 \%$ & $96 \%$ & \multirow{2}{*}{0.301} \\
\hline Other race & $13 \%$ & $66 \%$ & $23 \%$ & \\
\hline NIHSS on admission (point) & $16 \pm 6.7$ & $15 \pm 6.2$ & $20 \pm 7.4$ & 0.006 \\
\hline APACHE score & $17 \pm 7.5$ & $16 \pm 6.1$ & $24 \pm 8.6$ & 0.004 \\
\hline Baseline SBP (mmHg) & $156 \pm 37$ & $164 \pm 36.2$ & $130 \pm 27.4$ & $<0.001$ \\
\hline $48 \mathrm{~h}$ SBP average $(\mathrm{mmHg})$ & $136 \pm 16.1$ & $138 \pm 14.9$ & $127 \pm 16.9$ & 0.003 \\
\hline 48 h SBP VC (mmHg) & $0.09 \pm 0.07$ & $0.08 \pm 0.060$ & $0.12 \pm 0.107$ & 0.051 \\
\hline Baseline DBP (mmHg) & $91 \pm 21$ & $95 \pm 20.7$ & $79 \pm 19.4$ & 0.001 \\
\hline $48 \mathrm{~h}$ DBP average $(\mathrm{mmHg})$ & $73.9 \pm 10.9$ & $75 \pm 11.1$ & $70 \pm 9.2$ & 0.049 \\
\hline 48 h DBP VC $(\mathrm{mmHg})$ & $0.09 \pm 0.08$ & $0.08 \pm 0.082$ & $0.10 \pm 0.089$ & 0.376 \\
\hline $\mathrm{T}\left({ }^{\circ} \mathrm{C}\right)$ & $36.8 \pm 0.80$ & $36.8 \pm 0.71$ & $36.8 \pm 1.07$ & 0.944 \\
\hline $48 \mathrm{~h} \mathrm{~T}$ average $\left({ }^{\circ} \mathrm{C}\right)$ & $36.8 \pm 1.74$ & $36.8 \pm 1.91$ & $36.7 \pm 0.88$ & 0.747 \\
\hline $48 \mathrm{~h} \mathrm{TVC}\left({ }^{\circ} \mathrm{C}\right)$ & $0.002 \pm 0.04$ & $0.02 \pm 0.049$ & $0.02 \pm 0.014$ & 0.738 \\
\hline $\mathrm{CBG}(\mathrm{mg} / \mathrm{dL})$ & $150 \pm 28.3$ & $150 \pm 27.6$ & $149 \pm 30.8$ & 0.880 \\
\hline 48 h CBG average (mg/dL) & $147 \pm 36.3$ & $144.4 \pm 32.1$ & $159 \pm 46.2$ & 0.075 \\
\hline 48 h CBG VC (mg/dL) & $0.16 \pm 0.20$ & $0.15 \pm 0.210$ & $0.18 \pm 0.154$ & 0.509 \\
\hline Infection & $50 \%$ & $54 \%$ & $39 \%$ & 0.316 \\
\hline Previous myocardial infarction & $12 \%$ & $6 \%$ & $30 \%$ & 0.006 \\
\hline Acute myocardial infarction (during ICU stay) & $4 \%$ & $1 \%$ & $13 \%$ & 0.053 \\
\hline Thrombolysis & $12 \%$ & $13 \%$ & $9 \%$ & 0.613 \\
\hline Hemorrhagic transformation & $77 \%$ & $79 \%$ & $70 \%$ & 0.324 \\
\hline Creatinine (mg/dL) & $1.3 \pm 1.08$ & $1.17 \pm 0.93$ & $1.68 \pm 1.42$ & 0.056 \\
\hline Previous arterial hypertension & $77 \%$ & $79 \%$ & $70 \%$ & 0.324 \\
\hline Previous diabetes mellitus & $34 \%$ & $33 \%$ & $35 \%$ & 0.898 \\
\hline
\end{tabular}

Table 3. Adjusted odds ratios by backward stepwise multiple logistic regression analysis for the association of SBP in the first 48 hours of stroke onset with death in ischemic stroke patients.

\begin{tabular}{|c|c|c|c|c|}
\hline \multirow{2}{*}{ Variables } & \multirow{2}{*}{ OR } & \multicolumn{2}{|c|}{$95 \%$ ilC for OR } & \multirow{2}{*}{$\mathrm{p}$-value } \\
\hline & & Lower & Upper & \\
\hline \multicolumn{5}{|l|}{ Step 1} \\
\hline Age (year) & 1.033 & 0.985 & 1.085 & 0.181 \\
\hline NIHSS (point) & 1.074 & 0.983 & 1.172 & 0.113 \\
\hline 48 h SBP VC (mmHg) & 0.245 & 0.011 & 145.206 & 0.666 \\
\hline Acute myocardial infarction during hospitalization or admission & 2.292 & 0.455 & 11.547 & 0.315 \\
\hline Creatinine (mg/dL) & 1.470 & 0.936 & 2.307 & 0.094 \\
\hline 48 h CBG average (mg/dL) & 1.007 & 0.991 & 1.023 & 0.400 \\
\hline $48 \mathrm{~h}$ SBP average (mmHg) & 0.960 & 0.923 & 0.999 & 0.043 \\
\hline Thrombolysis & 4.038 & 1.245 & 13.096 & 0.020 \\
\hline \multicolumn{5}{|l|}{ Step 5} \\
\hline Age (year) & 1.090 & 1.041 & 0.994 & 0.086 \\
\hline NIHSS (point) & 1.087 & 1.001 & 1.180 & 0.046 \\
\hline $48 \mathrm{~h}$ SBP average $(\mathrm{mmHg})$ & 0.960 & 0.926 & 0.996 & 0.030 \\
\hline Creatinine (mg/dL) & 1.516 & 0.987 & 2.327 & 0.057 \\
\hline Thrombolysis & 4.204 & 1.345 & 13.138 & 0.014 \\
\hline
\end{tabular}

Data presented as the mean \pm standard deviation or percent (\%). IS: ischemic stroke; NIHSS: National Institute of Health Stroke Scale; 48 h SBP VC: systolic BP variation coefficient at 48 hours after admission; $48 \mathrm{~h} \mathrm{CBG}$ average: average of capillary blood glucose at 48 hours after admission; $48 \mathrm{~h}$ SBP average: average of systolic BP during 48 hours after admission; Bold indicates statistical significance of $<0.05$. 
Table 4. Post hoc logistic regression analysis including confounders associated with low BP.

\begin{tabular}{lcccc}
\hline \multirow{2}{*}{ Variable } & \multirow{2}{*}{ OR } & \multicolumn{2}{c}{$95 \% \mathrm{Cl}$ for OR } & \multirow{2}{*}{$\mathrm{p}$} \\
\cline { 3 - 4 } & & Lower & Upper & \\
\hline 48 h SBP average $(\mathrm{mmHg})$ & 0.961 & 0.929 & 0.995 & 0.024 \\
Infection & 0.607 & 0.217 & 1.692 & 0.339 \\
\hline Myocardial infarction & 3.894 & 1.007 & 15.068 & 0.049 \\
\hline
\end{tabular}

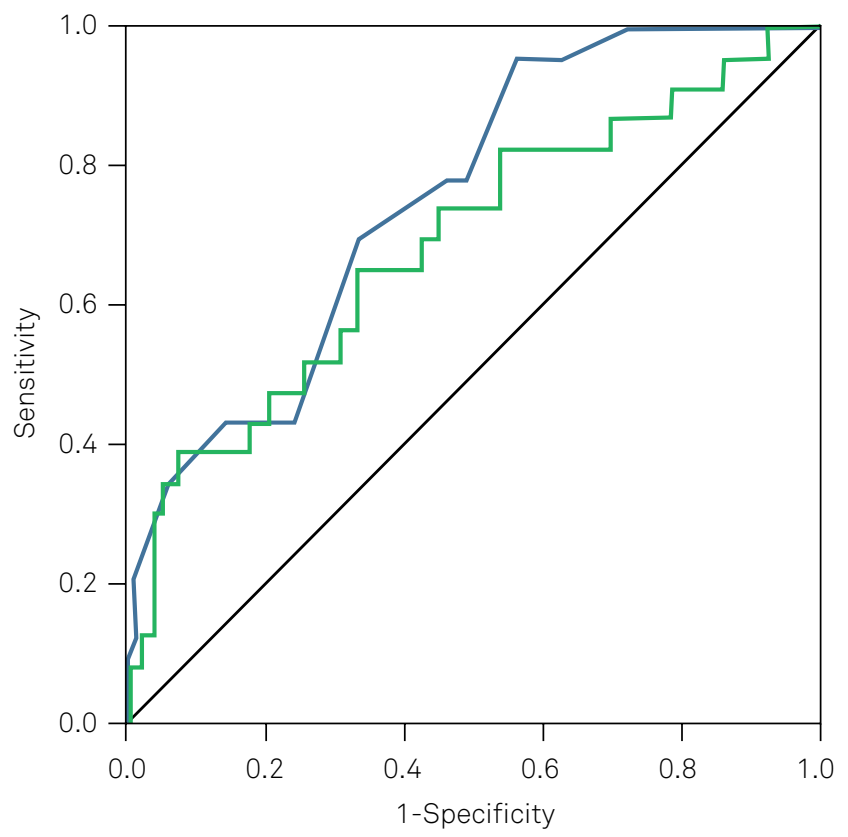

AUC/SBP admission $: 0.75$ ic $95 \%(0.65-0.86) \mathrm{P}<0.01$

Cutoff< $147 \mathrm{~mm}$ Hg; sens: 0.7; spec.: 0.67

AUC/SBP ${ }_{\text {mean } 24 h}: 0.74$ ic95\% (0.63-0.84) P<0.01

Cutoff< $131 \mathrm{~mm}$ Hg; sens: 0.65; spec.: 0.67

Figure 2. ROC curve between systolic blood pressure and outcome in ischemic stroke.

infarction and infection. Moreover, even excluding patients deceased from infection or cardiogenic shock (post hoc analysis not shown in the results) BP was lower among the 20 patients deceased from purely neurologic complications $(131 \pm 17.6 \mathrm{~mm}$ $\mathrm{Hg}$ ) than among the survivors ( $140 \pm 15.7 \mathrm{~mm} \mathrm{Hg}$; $=0.02)$. Conversely, myocardial infarction and cardiogenic shock may contribute to fatality among these patients independent of neurological factors. Therefore, these factors, in addition to low $\mathrm{BP}$, may potentiate deleterious effects on the penumbra zone during cerebral ischemia. A seminal study has shown that the restoration of blood flow in acute IS cases could improve the outcome in these patients ${ }^{31}$. In an experimental study, an artificial increase in BP promoted an improvement in the ischemic core and penumbra zone ${ }^{32}$.

During hospitalization, no patient presented with SBP $>180 \mathrm{~mm} \mathrm{Hg}$, making it challenging to confirm if there was a bimodal distribution for BP and risk of death from stroke from our study results. Antihypertensive treatment was more common in survivors than in deceased patients, so antihypertensive treatment cannot be attributed as a cause of mortality. On the other hand, we cannot rule out that the lack of antihypertensive cardioprotective drugs among the patients who died could have influenced, at least partially, the lethality ratio.

In the present study, SBP was assessed over DBP because it has a more accurate prognostic significance in the predominant age of the patients studied. In this age group, the rigidity of large arteries may explain this phenomenon ${ }^{32}$.

We observed that the case fatality ratio of stroke in the present study was $21 \%$ over the total period of seven days. In the published literature, lethality in the first 30 days after IS is approximately $10 \%^{33}$. The high lethality in our patient population may be explained by the fact that we studied ICU patients, who often present with a more severe stroke. The high NIHSS scores observed corroborate this idea; patients with an NIHSS score less than 5 points are often discharged quickly, and patients with scores above 14 frequently need long-term ICU care $^{34}$.

It is important to emphasize that the sample in the current study comprised stroke patients admitted in ICU. The NIHSS scores of our patients were very high, and there were patients with compromised consciousness and many comorbidities. These characteristics make the management of BP a very difficult challenge in these patients, and these facts must be taken into account in the interpretation of our findings. On the other hand, this study contributes to the knowledge of acute BP management in ICU stroke patients that is more relevant nowadays because of the possibility of thrombolysis and thrombectomy. It is of note that BP control must be initiated during prehospital assistance and be maintained not only through the hospital/ICU phase, but for the whole life of the patients.

\section{Limitations}

The greatest limitation of this study was the relatively small sample size. However, patients were recruited from the ICU, which provided information on a specific highrisk patient group. It would have been better to take into account the confounding variables-the creatinine clearance and cardiac output-instead of myocardial infarction and creatinine. But cardiac output and creatinine clearance are measurements performed in only a few patients in the ICU. Therefore, as a substitute to cardiac and renal involvement, we used infarction and creatinine. Another limitation, due to the use of conventional brain computerized tomography, in this study, we did not evaluate the penumbra zone for IS or the edema zone in HS. Finally, we did not assess atrial fibrillation (persistent or paroxysmal). Additional study strengths include the prospective study design and addressing a topical subject-prognostic factors of stroke in the acute phase in Brazilian ICU patients, which has a dearth of published research. 
In conclusion, there was a negative association between BP and the case fatality ratio of acute phase IS stroke patients in ICU, even after adjustment for cardiogenic shock and infection. This result indicates an independent effect of low BP. Values of SBP below $147 \mathrm{~mm} \mathrm{Hg}$ on admission or $131 \mathrm{~mm} \mathrm{Hg}$ within the first 48 hours were associated with the highest risk of death. There was no relationship between BP and outcome in HS. Our results are a contribution to the study of prognostic factors in the acute phase of stroke in ICU patients.

\section{References}

1. Grysiewicz RA, Thomas K, Pandey DK. Epidemiology of ischemic and hemorrhagic stroke: incidence, prevalence, mortality, and risk factors. Neurol Clin. 2008 Nov;26(4):871-95. https://doi.org/10.1016/j.ncl.2008.07.003

2. Garritano CR, Luz PM, Pires ML, Barbosa MT, Batista KM. Analysis of the mortality trend due to cerebrovascular accident in Brazil in the XXI century. Arq Bras Cardiol. 2012;98(6):519-27. https://doi.org/10.1590/S0066-782X2012005000041

3. Instituto Brasileiro de Geografia e Estatística. Sistema de Informação Hospitalar do SUS (SIH/SUS). Rio de Janeiro, RJ: IBGE; 2009 [cited 2013 Oct 10]. Available on: http://ces.ibge.gov.br/pt/ base-de-dados/metadados/ministerio-da-saude/sistema-deinformacoes-hospitalares-do-sus-sih-sus

4. O'Donnell MJ, Xavier D, Liu L, Zhang H, Chin SL, RaoMelacini P et al. Risk factors for ischaemic and intracerebral haemorrhagic stroke in 22 countries (the Interstroke study): a case-control study. Lancet. 2010 Jul;376(9735):112-23. https://doi.org/10.1016/S0140-6736(10)60834-3

5. Dunbabin DW, Sandercock PA. Preventing stroke by the modification of risk factors. Stroke. 1990 Dec;21(12 Suppl):IV36-9.

6. Nogueira D, Faerstein E, Coeli CM, Chor D, Lopes CS, Werneck GL. Awareness, treatment, and control of arterial hypertension: PróSaúde Study, Brazil. Rev Panam Salud Publica. 2010 Feb;27(2):103-9. Portuguese. https://doi.org/10.1590/S1020-49892010000200003

7. Gagliardi RJ. Hipertensão arterial e AVC. ComCiência.2009;(109).

8. Adams HP Jr, Bendixen BH, Kappelle LJ, Biller J, Love BB, Gordon $\mathrm{DL}$ et al. Classification of subtype of acute ischemic stroke: definitions for use in a multicenter clinical trial. TOAST. Trial of Org 10172 in Acute Stroke Treatment. Stroke. 1993 Jan;24(1):35-41. https://doi.org/10.1161/01.STR.24.1.35

9. Dahlöf B, Devereux RB, Kjeldsen SE, Julius S, Beevers G, Faire U et al. Cardiovascular morbidity and mortality in the Losartan Intervention for Endpoint reduction in hypertension study (LIFE): a randomized trial against atenolol. Lancet. 2002 Mar;359(9311):996-1003. https://doi.org/10.1016/S0140-6736(02)08089-3

10. Spence JD. Treating hypertension in acute ischemic stroke. Hypertension. 2009 Oct;54(4):702-3. https://doi.org/10.1161/HYPERTENSIONAHA.109.134486

11. Geeganage CM, Bath PM. Relationship between therapeutic changes in blood pressure and outcomes in acute stroke: a metaregression. Hypertension. 2009 Oct;54(4):775-81. https://doi.org/10.1161/HYPERTENSIONAHA.109.133538

12. Massaro AR. Hipertensão arterial e acidente vascular cerebral: as bases científicas para a decisão terapêutica. Rev Soc Cardiol Estado de São Paulo. 2008;18(2):182-92.

13. Leonardi-Bee J, Bath PM, Phillips SJ, Sandercock PA; IST Collaborative Group. Blood pressure and clinical outcomes in the International Stroke Trial. Stroke. 2002 May;33(5):1315-20. https://doi.org/10.1161/01.STR.0000014509.11540.66

14. Tikhonoff V, Zhang H, Richart T, Staessen JA. Blood pressure as a prognostic factor after acute stroke. Lancet Neurol. 2009 Oct;8(10):938-48. https://doi.org/10.1016/S1474-4422(09)70184-X

15. Vemmos KN, Tsivgoulis G, Spengos K, Zakopoulos N, Synetos A, Manios E et al. U-shaped relationship between mortality and admission blood pressure in patients with acute stroke. J Intern Med. 2004 Feb;255(2):257-65. https://doi.org/10.1046/j.1365-2796.2003.01291.x

16. Boreas AM, Lodder J, Kessels F, de Leeuw PW, Troost J. Prognostic value of blood pressure in acute stroke.J Hum Hypertens. 2002 Feb;16(2):111-6. https://doi.org/10.1038/sj.jhh.1001304

17. Carlberg B, Asplund K, Hägg E. The prognostic value of admission blood pressure in patients with acute stroke. Stroke. 1993 Sep;24(9):1372-5. https://doi.org/10.1161/01.STR.24.9.1372

18. Milhaud D, Popp J, Thouvenot E, Heroum C, Bonafé A. Mechanical ventilation in ischemic stroke.J Stroke Cerebrovasc Dis. 2004 Jul-Aug;13(4):183-8. https://doi.org/10.1016/j.jstrokecerebrovasdis.2004.06.007

19. Golestanian E, Liou JI, Smith MA. Long-term survival in older critically ill patients with acute ischemic stroke. Crit Care Med. 2009 Dec;37(12):3107-13. https://doi.org/10.1097/CCM.0b013e3181b079b2

20. Lan MY, Wu SJ, Chang YY, Chen WH, Lai SL, Liu JS. Neurologic and non-neurologic predictors of mortality in ischemic stroke patients admitted to the intensive care unit. J Formos Med Assoc. 2006 Aug;105(8):653-8. https://doi.org/10.1016/S0929-6646(09)60164-9

21. Lahiri S, Mayer SA, Fink ME, Lord AS, Rosengart A, Mangat HS et al. Mechanical Ventilation for Acute Stroke:A Multi-state Population-Based Study. Neurocrit Care. 2015 Aug;23(1):28-32. https://doi.org/10.1007/s12028-014-0082-9

22. Moon BH, Park SK, Jang DK, Jang KS, Kim JT, Han YM. Use of APACHE II and SAPS II to predict mortality for hemorrhagic and ischemic stroke patients. J Clin Neurosci. 2015 Jan;22(1):111-5. https://doi.org/10.1016/j.jocn.2014.05.031

23. Handschu R, Haslbeck M, Hartmann A, Fellgiebel A, Kolominsky-Rabas P, Schneider D et al. Mortality prediction in critical care for acute stroke: severity of illness-score or coma-scale? J Neurol. 2005 Oct;252(10):1249-54. https://doi.org/10.1007/s00415-005-0853-5

24. Riachy M, Sfeir F, Sleilaty G, Hage-Chahine S, Dabar G, Bazerbach Tet al. Prediction of the survival and functional ability of severe stroke patients after ICU therapeutic intervention. BMC Neurol. 2008 Jun;8:24. https://doi.org/10.1186/1471-2377-8-24

25. Jeng JS, Huang SJ, Tang SC, Yip PK. Predictors of survival and functional outcome in acute stroke patients admitted to the stroke intensive care unit. J Neurol Sci. 2008 Jul;270(1-2):60-6. https://doi.org/10.1016/j.jns.2008.01.015

26. Cincura C, Pontes-Neto OM, Neville IS, Mendes HF, Menezes DF, Mariano DC et al. Validation of the National Institutes of Health Stroke Scale, modified Rankin Scale and Barthel Index in Brazil: the role of cultural adaptation and structured interviewing. Cerebrovasc Dis. 2009;27(2):119-22. https://doi.org/10.1159/000177918

27. Bursac Z, Gauss CH, Williams DK, Hosmer DW. Purposeful selection of variables in logistic regression. Source Code Biol Med. 2008 Dec;3(12):17-25. https://doi.org/10.1186/1751-0473-3-17

28. Alonso A, Ebert AD, Kern R, Rapp S, Hennerici MG, Fatar M. Outcome predictors of acute stroke patients in need of 
intensive care treatment. Cerebrovasc Dis. 2015;40(1-2):10-7. https://doi.org/10.1159/000430871

29. Anderson CS, Heeley E, Huang Y, Wang J, Stapf C, Delcourt C et al. Rapid blood-pressure lowering in patients with acute intracerebral hemorrhage. N Engl J Med. 2013 Jun;368(25):2355-65. https://doi.org/10.1056/NEJMoa1214609

30. Olsen TS, Larsen B, Herning M, Skriver EB, Lassen NA. Blood flow and vascular reactivity in collaterally perfused brain tissue. Evidence of an ischemic penumbra in patients with acute stroke. Stroke. 1983 MayJun;14(3):332-41. https://doi.org/10.1161/01.STR.14.3.332

31. Shin HK, Nishimura M, Jones PB, Ay H, Boas DA, Moskowitz MA et al. Mild induced hypertension improves blood flow and oxygen metabolism in transient focal cerebral ischemia. Stroke. 2008 May;39(5):1548-55. https://doi.org/10.1161/STROKEAHA.107.499483

32. Agabiti-Rosei E, Muiesan ML. Carotid atherosclerosis, arterial stiffness and stroke events. Adv Cardiol. 2007;44(10):173-86. https://doi.org/10.1159/000096729

33. Bamford J, Dennis M, Sandercock P, Burn J, Warlow C. The frequency, causes and timing of death within 30 days of a first stroke: the Oxfordshire Community Stroke Project. J Neurol Neurosurg Psychiatry. 1990 Oct;53(10):824-9. https://doi.org/10.1136/jnnp.53.10.824

34. Costa FA, Silva DL, Rocha VM. [The neurological state and cognition of patients after a stroke]. Rev Esc Enferm USP. 2011 Oct;45(5):1083-8. Portuguese. http://dx.doi.org/10.1590/S0080-62342011000500008 